\title{
SHORT COMMUNICATION \\ WING SHAPE VARIATIONS OF MALAYSIAN FORENSIC SCUTTLE FLIES (DIPTERA: PHORIDAE) INCLUDE SEXUAL DIMORPHISMS
}

\author{
JULIANA KRISTINE ANTHONY ${ }^{1}$, HENRY DISNEY² AND RAJA MUHAMMAD ZUHA*1,3 \\ ${ }^{1}$ Forensic Science Programme, School of Applied Health Sciences, Faculty of Health Sciences, ${ }^{3}$ Center for Insect Systematics, \\ Faculty of Science \& Technology, Universiti Kebangsaan Malaysia, Basement 1, Tun Seri Lanang Library, 43600 UKM \\ Bangi, Selangor, Malaysia. ${ }^{2}$ Department of Zoology, University of Cambridge, Downing Street, Cambridge CB2 3EJ, United \\ Kingdom.
}

*Corresponding author: rmzuha@ukm.edu.my

Submitted final draft: 13 February 2020 Accepted: 28 March 2020

http://doi.org/10.46754/jssm.2020.08.017

\begin{abstract}
Geometric morphometric analysis recently has expanded to insects of forensic importance, mainly adult flies, as correct and valid species identification is important in forensic entomology. The objective of this research was to investigate morphological variations between two forensically important scuttle flies (Diptera: Phoridae) in Malaysia, i.e. Megaselia scalaris (Loew, 1866) and Megaselia spiracularis Schmitz, 1938, based on wing shape analysis. A total of 16 geometrical landmarks was defined and analysed with geometric morphometric procedures using MorphoJ software. Wing centroid size, which represented wing shape, was statistically different between species and sexes. By using residuals from the allometric effect, canonical variate analysis separated all defined groups in different distinct clusters and further cross validated by both species and sexes. Between species, male M. scalaris had broader wing shape than male M. spiracularis, whilst in the female, M. scalaris had a narrower shape at the tip of the wing. Within M. scalaris group, females had broader wing shape at the base than males, whereas in M. spiracularis, the females had narrower shape at the base of the wing than the males. The geometric morphometric analysis in distinguishing forensically important species could be expanded for further investigation, especially in Phoridae family.
\end{abstract}

Keywords: Geometric morphometric analysis, forensic entomology, centroid size, canonical variate analysis, wing shape analysis.

Abrreviations: GMA - geometric morphometric analysis; mPMI - minimum post mortem interval.

\section{Introduction}

Megaselia scalaris (Loew, 1866) and Megaselia spiracularis Schmitz, 1938 are forensically important scuttle flies (Diptera: Phoridae), commonly found indoors and in concealed environments (Greenberg \& Wells, 1998; Kumara et al., 2012; Thevan et al., 2010; Zuha et al., 2016). Their small appearance, approximately $2.0 \mathrm{~mm}$, enables them to penetrate through small openings to reach decomposing corpses earlier than other forensic flies such as the Calliphoridae and Sarcophagidae (Catts \& Goff, 1992). In the absence of other sarcosaprophagous flies, these scuttle flies can be primary reference to estimate minimum post mortem interval (mPMI) (Campobasso et al.,
2004; Reibe \& Madea, 2010). These two species are also considered as medically important flies as they can cause myiasis in humans and animals (Ghavami \& Djalilvand, 2015; Komori et al., 1978; Singh \& Rana, 1989; Vanin et al., 2013) and they feed on a broad spectrum of decaying organic sources (Disney, 2008).

Megaselia scalaris could thrive on wide range organic materials and has been used as an experimental subject in developmental biology (Trumble \& Pienkowski, 1979; Thomas et al., 2016), physiology (Harrison \& Cooper, 2003) and contaminant/pollutant bioassays (Trumble \& Jensen, 2004; Pennington et al., 2017). Disney (2008) summarized the developmental duration of $M$. scalaris at various temperatures 
based on studies by different authors from 1922 to 2004 but the biological information of this species from Malaysia and neighbouring regions is still scarce (Zuha \& Omar, 2014; Idris et al., 2001; Tumrasvin et al., 1977). Even though $M$. scalaris and M. spiracularis have been found co-existing in natural environments (Kumara et al., 2012; Thevan et al., 2010; Zuha et al., 2016), information on the developmental duration of $M$. spiracularis is currently limited to pupal stage which on average ranged at $177.10 \pm 1.65$ hours at $33^{\circ} \mathrm{C}$ to $379.68 \pm 2.20$ hours at $21^{\circ} \mathrm{C}$ (Feng \& Liu, 2013). The dearth of developmental data of these two species warrants more studies to be conducted as their role is significant in forensic entomology.

Due to morphological diversity of scuttle flies and their roles in many fields, it is important to correctly discriminate these two species when being used as forensic evidence. In forensic entomology, incorrect species identification might cause inaccuracy of age estimation, resulting in erroneous calculation of mPMI. Based on morphological characteristics of adult male and female M. scalaris and M. spiracularis, these two species can be differentiated by microscopy techniques. The presence of hairs on mesopleuron of male and female $M$. spiracularis distinguishes them from M. scalaris (Disney, 2009). A male $M$. spiracularis can be compared with a male $M$. scalaris by having large abdominal spiracles, whilst female M. scalaris can be recognised from $M$. spiracularis by its broad and short abdominal tergite 6 (Brown \& Oliver, 2007). In terms of sexual dimorphisms, adult females of both species are generally longer than males possibly due to fecundity advantage (Berns, 2013) and this feature was also observed in larval and pupal stages (Zuha \& Omar, 2014). However, in forensic practice, it is possible that improper preservation of scuttle flies, including these two species could cause the body to shrink and make identification based on thoracic and abdominal parts more difficult.

Although scuttle fly wing has been used as diagnostic part to distinguish between genera and species, systematic profile on their wings at present only relies on the venation characteristics and the traditional morphometrics of costal index, i.e. the length of costa divided by wing length, and costal ratios, i.e. the ratios of the length of the costal sections (Disney, 1994). In the current research, descriptions of adult male and female $M$. scalaris and M. spiracularis were extended to the profiles of their wing geometric morphometrics. This technique has been widely applied to classify and associate insect species, including forensically important flies, based on their phenetic relationships of shapes which could also visualise sexual shape dimorphisms across different species (Benitez, 2013; Bonduriansky, 2006). Furthermore, current geometric morphometric analysis (GMA) on forensically important flies is limited to wing shape profiles of Calliphoridae (Hall et al., 2014; Sontigun et al., 2017), Sarcophagidae (Sontigun et al. 2019), Muscidae (Grzywacz et al., 2017) and Piophilidae (Nuñez-Rodriguez \& Liria, 2017a), including some brief descriptions on larval mouthpars (Nuñez \& Liria, 2016; Sharanya \& Zuha, 2019). Therefore, the utilisation of GMA on $M$. scalaris and $M$. spiracularis wings will provide new extensions to its taxonomic profile, and possibly could be extended to other species of Phoridae.

\section{Materials and Methods}

\section{Sample Preparation}

Megaselia scalaris $($ Male $=30$, Female $=30)$ and M. spiracularis $($ Male $=30$, Female $=29)$ adults were obtained from stock colonies reared at Forensic Entomology Laboratory, Forensic Science Program, Universiti Kebangsaan Malaysia, Bangi. All specimens were at least three days old before preservation in $70 \%$ ethanol (Disney, 1994). Left wings of $M$. scalaris and $M$. spiracularis were selected as samples for this study. They were dissected based on prescribed techniques (Disney, 2001) and mounted in dorsal position on glass slides in Berlese fluid with $5 \mathrm{~mm}$ rounded coverslips. 


\section{Landmarks Acquisition and Data Analysis}

Images of the wings were acquired by using a stereomicroscope (Nikon, Japan) fitted with a 12-megapixel USB3.0 CMOS microscope camera (ToupCam, China). Wing images were converted to a readable format by using tpsUtil software (Version 1.74) and landmarks were plotted by using tpsDig2 software (Version 2.31). The 16 landmarks were chosen based on the generalised description of scuttle fly wing (Disney 1994): 1) Costagial break, 2) Humeral vein, 3) Vein 1 tip, 4) Vein 2 tip, 5) Vein 3 tip, 6) Tip of costal vein, 7) Outer vein 3 tip, 8) Basal vein 4, 9) Basal vein 5, 10) Basal vein 6, 11) Basal axillary margin, 12). Incision, 13) Vein 7 tip, 14) Vein 6 tip, 15) Vein 5 tip, 16) Vein 4 tip (Figure 1). These landmarks offer valid usability as they mainly include points at which two to three points in space meet (juxtapositions of tissues), and the farthest points from segments (extremal points) (Bookstein, 1991). Furthermore, the landmarks were ideally following the criteria in Zelditch et al. (2012) by having homologous anatomical loci, provide adequate coverage of the morphology, can be found repeatedly, do not switch positions relative to each other and lie within the same plane.

GMA of wing shape was carried out by using MorphoJ software (Klingenberg 2011), which includes visualisation of landmark shifts and canonical variate analysis. Assessment of group separations or discrimination was based on leave-one-out cross validation, optimized for multiple landmarks in discriminant function analysis in MorphoJ software. In SPSS Version 22 software, centroid sizes were classified based on sex and species as independent groups and analysed by using independent sample $t$-test $(\alpha=0.05)$. The centroid size of the wings, or the size of the wings based on the configuration of 16 landmarks, was represented by the square root of the sum of the squared distances between each landmark and the centroid of the wing (Zelditch et al., 2012). Alternatively, centroid size can also be considered as a measure of the amount of dispersion of landmarks around the 'center of gravity' (the centroid).

\section{Results and Discussion}

By using independent sample $t$-test, sexual shape dimorphisms were detected in both $M$. scalaris and $M$. spiracularis. In M. scalaris, mean centroid size of female $(2.76 \pm 0.14)$ was significantly higher than that of the male $(2.07 \pm 0.24), \quad t(58)=13.71, \quad p<0.001, \quad d=3.54$, while in M. spiracularis, mean centroid size of female (2.68 \pm 0.11$)$ was also significantly higher than that of male $(2.20 \pm 0.08), t(57)=18.94$, $p<0.001, d=4.93$. Variations between species were also observed in both sexes. Mean centroid size of male $M$. scalaris was significantly lower than $M$. spiracularis, $t(58)=2.95, \quad p<0.001$,

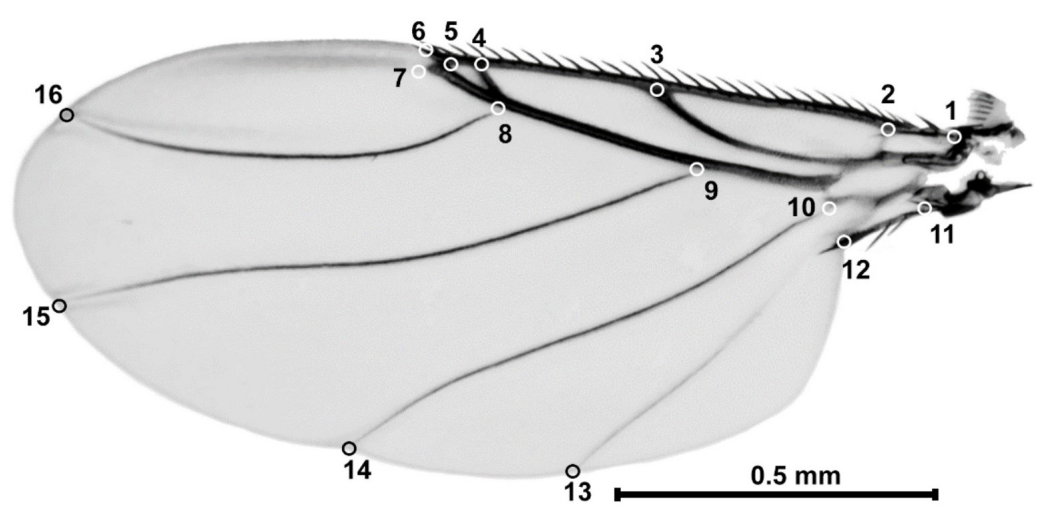

Figure 1: Morphological landmarks for GM analysis based on female M. scalaris left wing in dorsal view 
$d=0.76$ whilst mean centroid size of female M. scalaris was significantly higher than $M$. spiracularis, $t(57)=2.45, p<0.05, d=0.64$.

To assess whether there was any influence of size on the shape of Megaselia wings, regression analysis of Procrustes coordinates on centroid size was performed among species, pooled within species and for each species independently based on sex (permutation test 10,000 rounds in MorphoJ). The result was highly significant among species $(p<0.0001)$ and allometry was accounted for $23.76 \%$ of the total shape variations. For within species regression, the relationship was also highly significant $(p<0.0001)$ with $50.78 \%$ of shape could be explained by size. Allometry was accounted for $23.15 \%$ of the total shape variation in male $M$. scalaris and it was also highly significant $(p<0.0001)$, whilst in female, this relationship was accounted for $8.19 \%$ $(p<0.05)$. In M. spiracularis, wing size did not influence shape variations in male $(p=0.26)$ but the regression was significant in female with allometry accounted for $9.93 \%$ of the total shape variations $(p<0.05)$.

Sexual shape dimorphisms between $M$. scalaris and M. spiracularis can be visualised from the first two canonical variates $99.66 \%$ of total variations $(\mathrm{CV} 1=93.40 \%, \mathrm{CV} 2=6.32)$.

Scatter plot from the two canonical variates clearly separates the two species and indicates sexual shape dimorphisms with Mahalanobis distances among groups ranging from 3.04 to $13.83(p<0.0001)$ and Procrustes distance among groups ranging from 0.02 to $0.11(p<0.0001$ and $p<0.05$ for $M$. scalaris sexual shape dimorphism). Cross-validation test between species for both male and female reveals $100.00 \%$ correct classification. In $M$. scalaris, cross-validation test shows $100.00 \%$ correct classification of females and $96.67 \%$ of males, whilst in $M$. spiracularis, $96.55 \%$ were correctly classified into females and $100.00 \%$ into males (Figure 3).

Figure 4 shows variations of shapes based on relative visual comparisons of geometrical landmark residuals between two groups. Although wing morphologies of both sexes were almost visually identical, sexual shape dimorphisms in $M$. scalaris mostly occurred on basal axillary margin (landmark 11), followed by tip of vein 1 (landmark 3), tip of vein 2 (landmark 4), basal vein 5 (landmark 9) and tip of vein 4 (landmark 16). These variations could be observed on female wing by having broader basal baseline compared

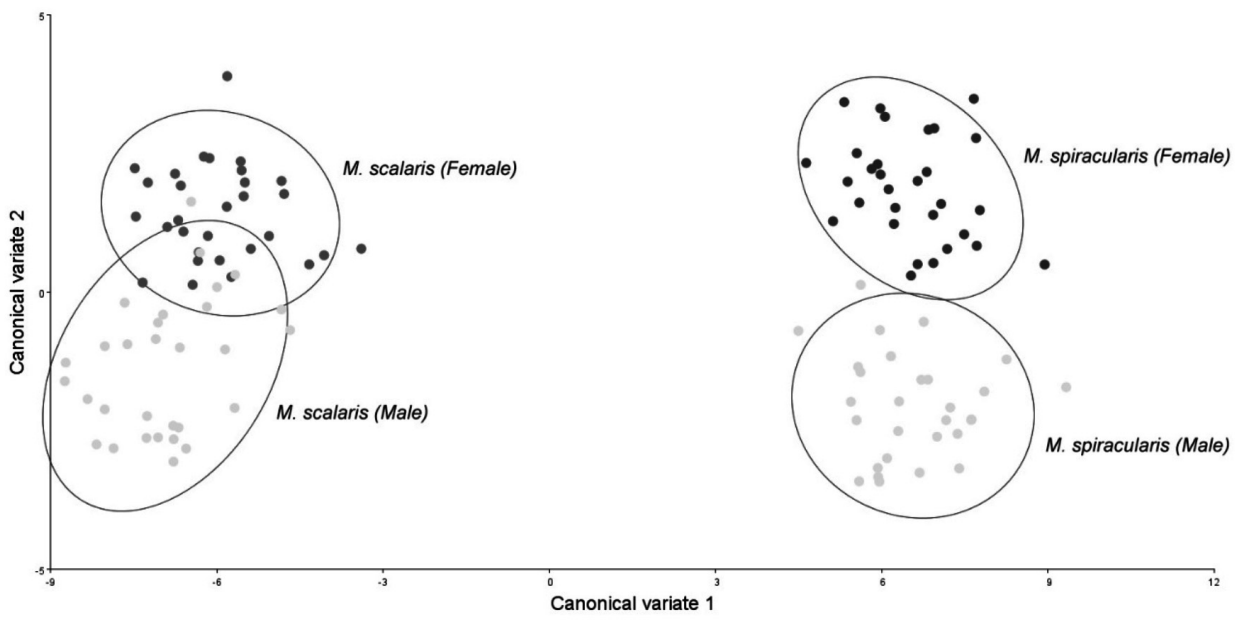

Figure 2: Scatter plot along CV1 (93.40 \%) and CV2 (6.32 \%) axes shows the variation in wing shapes grouped by equal frequency ellipse $(\mathrm{P}=0.9)$. The coordinates were clustered based on $M$. scalaris and $M$. spiracularis male and female 


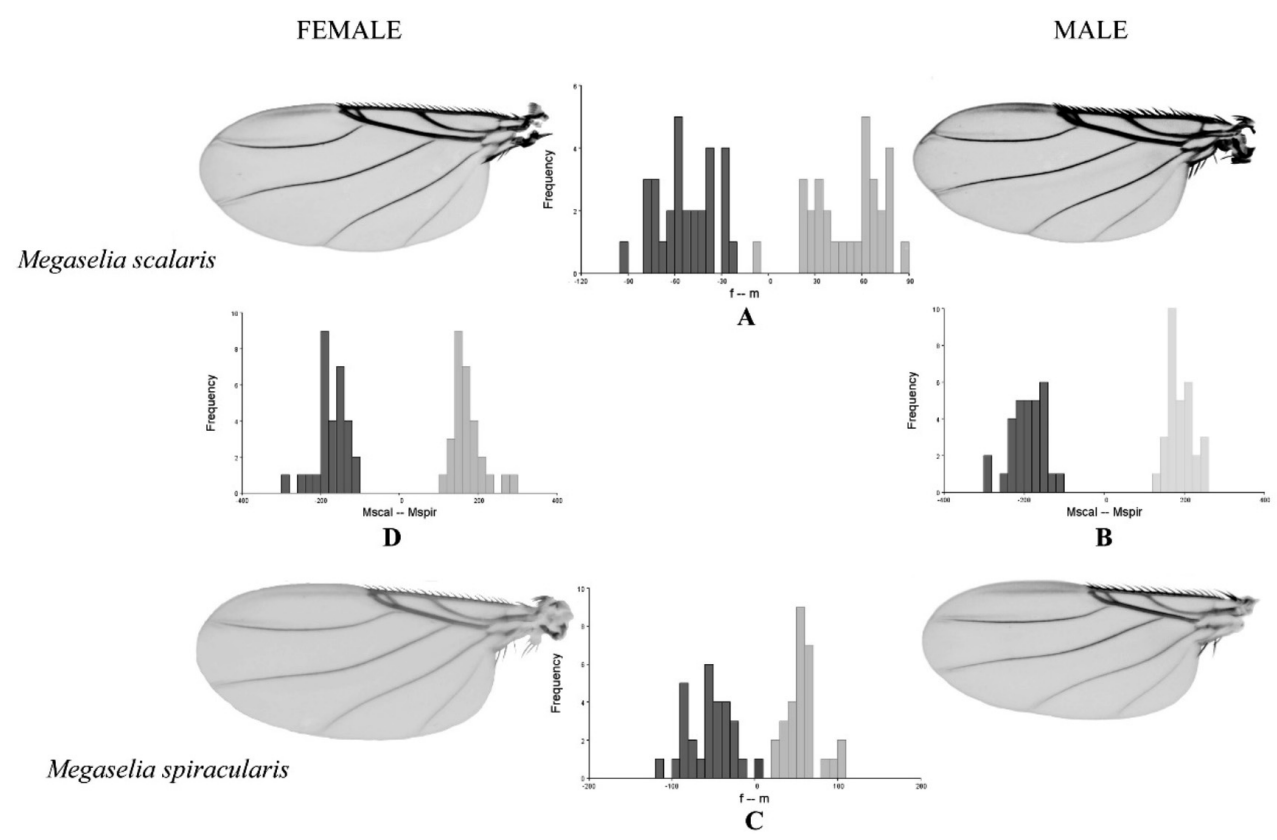

Figure 3: Cross validation tests between groups: A. M. scalaris female - male; B. M. scalaris male $-M$. spiracularis male; C. M. spiracularis female - male; and D. M. scalaris female - M. spiracularis male

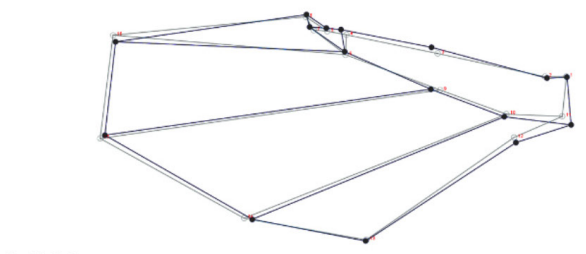

A

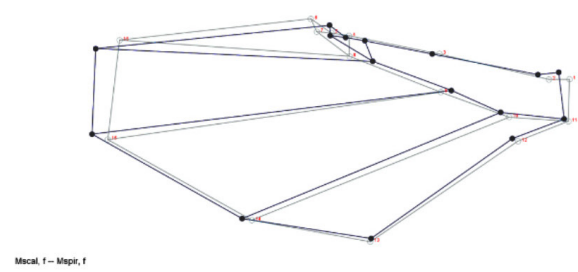

C

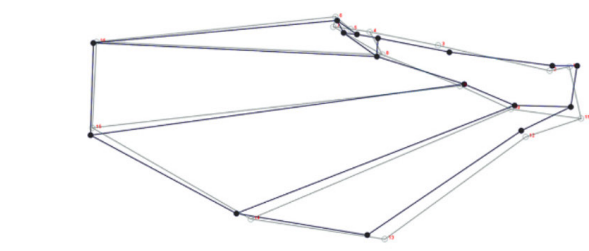

B



D

Figure 4: Variations of wing shapes based on allometric residuals from original mean landmark coordinates (black) to target mean landmark coordinates (grey). A: From M. scalaris female to M. scalaris male (Scale factor = 3); B. From M. spiracularis female to M. spiracularis male (Scale factor = 3); C. From M. scalaris female to M. spiracularis female (Scale factor =1); and D. From M. scalaris male to M. spiracularis male $($ Scale factor $=1)$ 
to male. However, variations were more observable in M. spiracularis than M. scalaris based on dispositions of mean landmark coordinates between males and females. In $M$. spiracularis, variations were observed on basal axillary margin (landmark 11), followed by tip of vein 7 (landmark 13), tip of vein 6 (landmark 14), tip of vein 1 (landmark 3 ) and outer tip of vein 3 (landmark 7). Overall, the shape of $M$. spiracularis wing in female was narrower at the base than its male. This information further elaborates sexual dimorphism characteristics of scuttle flies which were previously limited to differences in adult, larval and pupal size (Disney, 1994; Feng \& Liu, 2013; Zuha \& Omar. 2014). In contrast with wing shape of Calliphoridae, such as Chrysomya albiceps (Wiedemann, 1819), Chrysomya megacephala (Fabricius, 1794) and Lucilia cuprina (Wiedemann, 1830) (Nuñez-Rodriguez \& Liria, 2017b), the Phoridae in current study were more distinctive and supported by the significant differences in mean centroid sizes $(p<0.001)$. Sexual shape dimorphism was also reported in another forensic species, Piophila casei (Linnaeus, 1758) but there was no significant difference in mean centroid size (Nuñez-Rodríguez \& Liria, 2017a).

Between species in male, displacements of residuals occurred at most of the landmarks except for minimal changes on the tip of vein 1 (landmark 3) and tip of vein 7 (landmark 13), whilst in females, displacements were also observed in all landmarks with small variations on landmark the tip of vein 1 (landmark 3), basal axillary margin (landmark 11), the incision (landmark 12) and tip of vein 7 (landmark 13).

From the results, $M$. scalaris and $M$. spiracularis could be discriminated based on wing geometrical landmark coordinates. This new information expands the morphological differences of $M$. scalaris and $M$. spiracularis beyond the characteristics found on the thoracic and abdominal regions (Brown \& Oliver, 2007; Disney, 1989; 2009). The distinctions between these two species based on GMA were also consistent with current taxonomic descriptions than use the scale ratios between costal length and wing length (Borgmeier, 1966; 1967).

We also found that GMA was useful and efficient to distinguish insect species apart from its wider function to analyse biological shapes of vertebrates (Bookstein, 1991; Webster \& David Sheets, 2010; Zelditch et al., 2012). Previously in forensic entomology, the application of morphometry in insects was limited to the traditional method, i.e. measuring inter landmarks distances (Daly, 1985) but recently the application of GMA has been expanded to the fly species of forensic importance. For instance, in Calliphoridae, genus Chrysomya RobineauDesvoidy, 1830, Lucilia Robineau-Desvoidy, 1830 and Hemipyrellia Townsend, 1918 could be discriminated by canonical variate analysis with high cross validation percentage ( $>94.3 \%$ ) (Sontigun et al., 2017; Nuñez-Rodriguez \& Liria, 2017b). Although current study used 16 geometrical landmarks as compared to Sontigun et al., (2017) (19 landmarks) and NuñezRodriguez and Liria (2017b) (18 landmarks), correct reclassifications were high. However, future research should consider to increasing sample size as it could improve the reliability of this test.

\section{Conclusion}

This preliminary investigation proved that significant variations were identified in $M$. scalaris and M. spiracularis wing shape based on the centroid size and landmark displacements, with addition to their sexual shape dimorphisms. Apart from other morphological characteristics in both species, wing shape could be a reliable reference for identification process, especially for the purpose of species confirmation in forensic entomology. Additionally, these findings warranted further investigation into Phoridae in order to improve taxonomic descriptions based on wing characteristics using GMA.

\section{Acknowledgements}

The authors would like to thank the laboratory staffs of the Forensic Science Program, Faculty 
of Health Sciences, UKM for providing research equipment and facility. This research was funded by UKM Research Incentive Grant: GGP-2017036 of the corresponding author.

\section{References}

BBenitez, H. A. (2013). Chapter 3. Sexual dimorphism using geometric morphometric approach. In Moriyama, H. (Ed.). Sexual dimorphism. Intech open. Retrieved from https://www.intechopen.com/books/sexualdimorphism

Berns, C. M. (2013). Chapter 1. The evolution of sexual dimorphism: Understanding mechanisms of sexual shape difference In Moriyama, H. (Ed.). Sexual dimorphism. Intech open. Retrieved from https://www. intechopen.com/books/sexual-dimorphism

Bookstein, F. L. (1991). Morphometric tools for landmark data: Geometry and biology. Cambridge: Cambridge University Press.

Bonduriansky, R. (2006). Convergent evolution of sexual shape dimorphism in Diptera. Journal of Morphology, 267, 602-611.

Borgmeier, T. (1966). Studies on Indo-Australian phorid flies, based mainly on material of the Museum of Comparative Zoology and the United States National Museum (Diptera, Phoridae). Studia Entomologica, Petropolis, 9, 129-348.

Borgmeier, T. (1967). Studies on Indo-Australian phorid flies, based mainly on material of the Museum of Comparative Zoology and the United States National Museum (Diptera, Phoridae). Part II. Studia Entomologica, Petropolis, 10, 81-276.

Brown, B., \& Oliver, H. (2007). First records of Megaselia scalaris (Loew) and M. spiracularis Schmitz (Diptera: Phoridae) from New Zealand, with additional information on other worldwide species. New Zealand Entomologist, 30(1), 85-87.
Campobasso, C. P., Disney, R. H. L., \& Introna. F. (2004). A case of Megaselia scalaris (Loew) (Diptera: Phoridae) breeding in a human corpse. Aggrawal's Internet Journal of Forensic Medicine and Toxicology, 5(1), 3-5.

Catts, E., \& Goff, M. L. (1992). Forensic entomology in criminal investigations. Annual Review of Entomology, 37(1), 253-272.

Daly, H. V. (1985). Insect morphometrics. Annual Review of Entomology, 30, 415438.

Disney, R. H. L. (1989). Scuttle flies: The Phoridae (Genus Megaselia). The Royal Entomological Society Handbooks. Vol. 10. London: Royal Entomological Society.

Disney, R. H. L. (1994). Scuttle flies: The Phoridae. London: Chapman \& Hall.

Disney, R. H. L. (2001). The preservation of small Diptera. Entomologist's Monthly Magazine, 137, 155-159.

Disney, R. H. L. (2008). Natural history of the scuttle fly, Megaselia scalaris. Annual Review of Entomology, 53(1), 39-60.

Disney, R. H. L. (2009). Scuttle flies (Diptera: Phoridae) Part II: the genus Megaselia. Fauna of Arabia, 24, 249-357.

Feng, D. X., \& Liu, G. C. (2013). Pupal age estimation of forensically important Megaselia spiracularis Schmitz (Diptera: Phoridae). Forensic Science International, 231(1-3), 199-203.

Ghavami, M. B., \& Djalilvand, A. (2015). First record of urogenital myiasis induced by Megaselia scalaris (Diptera: Phoridae) from Iran. Journal of Arthropod- Borne Diseases, 9(2), 274-280.

Greenberg, B., \& Wells, J. (1998). Forensic use of Megaselia abdita and M. scalaris (Phoridae: Diptera): case studies, development rates, and egg structure. Journal of Clinical Forensic Medicine, 35(3), 203-209. 
Grzywacz, A., Ogiela, J., \& Tofilski, A. (2017). Identification of Muscidae (Diptera) of medico-legal importance by means of wing measurements. Parasitology Research, 116, 1495-1504.

Hall, M. J. R., MacLeod, N., \& Wardhana, A. H. (2014). Use of wing morphometrics to identify populations of the Old World screwworm fly, Chrysomya bezziana (Diptera: Calliphoridae): A preliminary study of the utility of museum specimens. Acta Tropica, 138, S49-S55.

Harrison, D. A., \& Cooper, R. L. (2003). Characterization of development, behavior and neuromuscular physiology in the phorid fly, Megaselia scalaris. Comparative Biochemistry and Physiology Part A: Molecular \& Integrative Physiology, 136(2), 427-439.

Idris, A. B., Abdullah, M., \& Lin, T. P. (2001). Effect of various diets on the development of scuttle fly, Megaselia scalaris (Loew) (Diptera: Phoridae), larvae and pupae and percent of adult emergence and longevity. Pakistan Journal of Biological Sciences, 4(3), 321-325.

Klingenberg, C. P. (2011). MorphoJ: An integrated software package for geometric morphometrics. Molecular Ecology Resources, 11(2), 353-357.

Komori, K., Hara, K., Smith, K. G. V., Oda, T., \& Karamine, D. (1978). A case of lung myiasis caused by larvae of Megaselia spiracularis Schmitz (Diptera: Phoridae). Transactions of Royal Society of Tropical Medicine \& Hygiene, 72(5), 467-470.

Kumara, T., Disney, R. H. L., Abu Hassan, A., Flores, M., Hwa, T. S., Mohamed, Z., CheSalmah, M. R., \& Bhupinder, S. (2012). Occurrence of oriental flies associated with indoor and outdoor human remains in the tropical climate of north Malaysia. Journal of Vector Ecology, 37(1), 62-68.

Nuñez, J., \& Liria, J. (2016). Cephalopharyngeal geometric morphometrics in three blowfly species (Diptera: Calliphoridae). Journal of Entomology and Zoology Studies, 4(1), 338-341.

Nuñez-Rodríguez, J. A., \& Liria, J. (2017). Geometric morphometrics sexual dimorphism in three forensically important species of blow fly (Diptera: Calliphoridae). Life: The Excitement of Biology, 4(4), 272284.

Pennington, M. J., Rothman, J. A. Jones, M. B., McFrederick, Q. S., Gan, J., \& Trumble, J. T. (2017). Effects of contaminants of emerging concern on Megaselia scalaris (Loew, Diptera: Phoridae) and its microbial community. Scientific Reports, 7, 8165.

Reibe, S., \& Madea, B. (2010). Use of Megaselia scalaris (Diptera: Phoridae) for post-mortem interval estimation indoors. Parasitology Research, 106(3), 637-640.

Sharanya, B., \& Zuha, R. M. (2019). A preliminary geometric morphometric assessment of two forensically important blow fly larvae in Malaysia, Chrysomya megacephala (Fabricius) and Chrysomya rufifacies (Macquart) (Diptera: Calliphoridae). Serangga 24(1), 70-79.

Singh, T. S., \& Rana, D. (1989). Urogenital myiasis caused by Megaselia scalaris (Diptera: Phoridae): A case report. Journal of Medical Entomology, 26(3), 228-229.

Sontigun, N., Samerjai, C., Sukontason, K., Wannasan, A., Amendt, J., Tomberlin, J. K., \& Sukontason, K. L. (2019). Wing morphometric analysis of forensically important flesh flies (Diptera: Sarcophagidae) in Thailand. Acta Tropica, 190, 312-319.

Sontigun, N., Sukontason, K. L., Zajac, B. K., Zehner, R., Sukontason, K., Wannasan, A., \& Amendt, J. (2017). Wing morphometrics as a tool in species identification of forensically important blow flies of Thailand. Parasites \& Vectors, 10(1), 229.

Thevan, K., Disney, R. H. L., \& Abu Hassan, A. (2010). First records of two species of 
Oriental scuttle flies (Diptera: Phoridae) from forensic cases. Forensic Science International, 195(1-3), e5-e7.

Thomas, J. K., Sanford, M. R., Longnecker, M., \& Tomberlin, J. K. (2016). Effects of temperature and tissue type on the development of Megaselia scalaris (Diptera: Phoridae). Journal of Medical Entomology, 53(3), 519-525.

Trumble, J. T., \& Jensen, P. D. (2004). Ovipositional response, developmental effects and toxicity of hexavalent chromium to Megaselia scalaris, a terrestrial detritivore. Archives of Environmental Contamination and Toxicology, 46, 372376.

Trumble, J. T., \& Pienkowski, R. L. (1979). Development and survival of Megaselia scalaris (Diptera: Phoridae) at selected temperatures and photoperiods. Proceedings of the Entomological Society of Washington, 81(2), 207-210.

Tumrasvin, W., Sucharit, S., \& Vutikes, S. (1977). Studies on the life history of Megaselia scalaris (Loew) in Thailand. Southeast Asian Journal of Tropical Medicine and Public Health, 8(1), 74-76.
Vanin, S., Mazzariol, S., Menandro, M. L., Lafisca, A., \& Turchetto, M. (2013). Myiasis by Megaselia scalaris (Diptera: Phoridae) in a phyton affected by pulmonitis. Journal of Medical Entomology, 50(1), 209-11.

Webster, M., \& David Sheets, H. (2010). A practical introduction to landmark-based geometric morphometrics. In J. Alroy and G. Hunt (Eds.), Quantitative methods in paleobiology. Paleontological Society Papers, 16,163-188.

Zelditch, M. L., Swiderski, D. L., \& David Sheets, H. (2012). Geometric morphometrics for biologists: A primer. London: Academic Press.

Zuha, R. M., Ankasha, S. J., Disney, R. H. L., \& Omar, B. (2016). Indoor decomposition study in Malaysia with special reference to the scuttle flies (Diptera: Phoridae). Egyptian Journal of Forensic Sciences, 6(3), 216-222.

Zuha, R. M., \& Omar, B. (2014). Developmental rate, size, and sexual dimorphism of Megaselia scalaris (Loew) (Diptera: Phoridae): Its possible implications in forensic entomology. Parasitology Research, 113(6), 2285-2294. 